\title{
BATTERY FOR EXTENDED TEMPERATURE RANGE EXOMARS ROVER MISSION
}

\author{
Steve $\operatorname{AMOS}^{(1)}$, Paul BROCHARD ${ }^{(2)}$ \\ (1) AIRBUS Defence and Space, Gunnels Wood Road, Stevenage - United Kingdom, Email: stephen.amos@airbus.com \\ ${ }^{(2)}$ Saft, Space and Defence Division, BP 1039, 86060 Poitiers - France,Email: paul.brochard@saftbatteries.com
}

\begin{abstract}
The robotic exploration of Mars plans to deliver a European rover on the surface of Mars during the RSP (Rover \& Surface Platform) mission. Exomars is a broad cooperation between ESA and Roscosmos, with important contribution from NASA.

NASA already sent several rovers on Mars using RTG (Radio isotopic Thermoelectric Generator) to provide electricity on-board. RTGs are not used by ESA, therefore an electrochemical storage system is developed for this mission.

Nevertheless, the rover is equipped with Radio-isotopic Heater Units (RHU) supplied by the Russians, which aim to prevent the internal temperature of the rover dropping below $-40^{\circ} \mathrm{C}$, whereas an external Rover temperature as low as $-125^{\circ} \mathrm{C}$, can be expected on the Martian surface. The drawback is that during the rover encapsulation and the cruise between the Earth and the red planet, the internal Rover temperature will reach $+40^{\circ} \mathrm{C}$ to $+50^{\circ} \mathrm{C}$ during months.
\end{abstract}

The rechargeable battery designed for the rover shall then withstand the high temperatures exposure followed by charge / discharge cycles at low temperatures when on surface of Mars.

Another point to highlight is that the mission objective is to try to find well-preserved organic material, particularly from the very early history of the planet, from the subsurface.

Consequently, the contamination of the rover and all its equipment must be controlled similar to medical tools to avoid depositing spores that could pollute the samples during the on surface phase of the mission.

This paper is presenting the innovative battery designed to withstand these extended operating temperatures while being able to power the rover during night and days (even during local sand storm).

The thermal control of the battery was of the utmost criticality to answer to this wide temperature range.

The rover design was well advanced when the battery development started, therefore adding challenging schedule and mass targets!

\section{THE EXOMARS MISSION}

The mission phases with the associated battery environment are summed up in the following table. A sol in a Martian "day" ( 1 sol $=24.66$ hours on Earth).

Table 1: Exomars mission phases

\begin{tabular}{|l|c|c|}
\hline \multicolumn{1}{|c|}{ Phase } & Duration & Temperature \\
\hline Storage & 15 months & $+22^{\circ} \mathrm{C}$ \\
\hline $\begin{array}{l}\text { Prelaunch encapsulated } \\
\text { (inside the rover) }\end{array}$ & 9 months & $+50^{\circ} \mathrm{C}$ \\
\hline Cruise (Earth $\rightarrow$ Mars) & 9 months & $+40^{\circ} \mathrm{C}$ \\
\hline Mars on-surface & 220 sols & $-40^{\circ} \mathrm{C}<\mathrm{T}<+50^{\circ} \mathrm{C}$ \\
\hline
\end{tabular}

The temperatures stated in the above table are those of the mounting plane below the battery (conductive coupling). The rover bathtub structure internal temperature can drop to $-115^{\circ} \mathrm{C}$ adding a radiative coupling with the external surfaces of the battery.

The battery is maintained during the storage phase up to the arrival on the Martian surface. This maintenance aims to keep a minimum state of charge of the battery and to balance it in order to avoid spread in cells' voltage. The battery will experience maximum of 140 cycles to maintain the optimum battery State of Charge (SOC) i.e. $50 \% \pm 10 \%$ for minimum fade and also for 3 health checks during the cruise of the rover.

When on-surface, the battery is charged during daylight with the solar panels after preheating to avoid too low charge temperature. It is delivering energy for peak demands during the day, and during the night when the solar panels are not illuminated. A typical 3-days electrical profile is given on Fig. 1.

It is supplying the scientific instruments and the locomotion subsystem to allow the rover travelling autonomously across the Martian surface. 


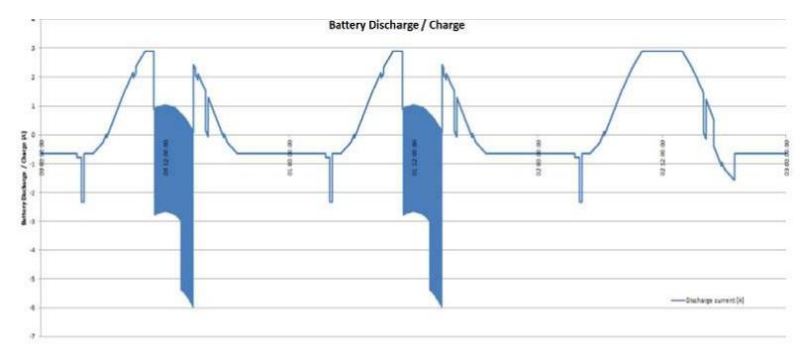

Figure 1. Battery typical 3-days electrical profile

\section{THE BATTERY DESIGN}

The battery contains the following hardware to fulfil its tasks:

- Electro-chemical cells

- Cabling \& inter-connections

- Structural parts

- Passive \& active thermal controls

- An isolation switch

- An embedded balancing system

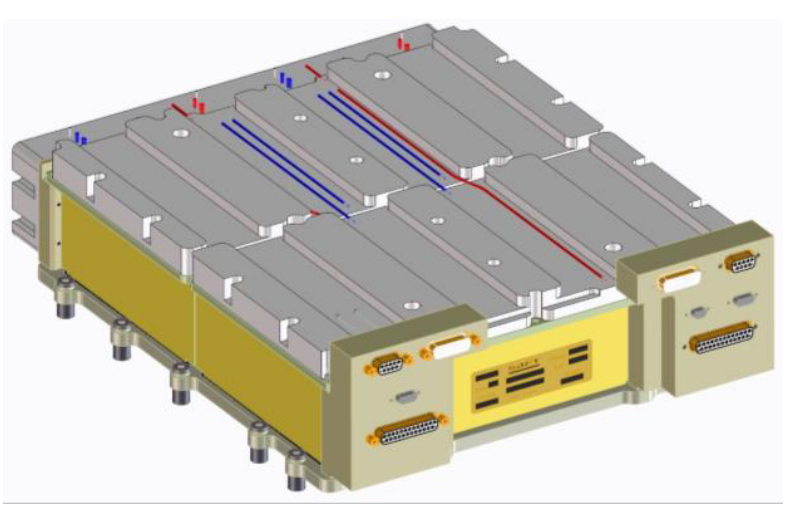

Figure 2. Exomars Rover battery

Electro-chemical Li-ion cells: MP176065 Xtd

Saft selected the MP176065Xtd cell (Xtd standing for Extended temperatures) to cope with the wide climatic range of the Exomars mission.
Manufacturer

Nameplate capacity

Nominal voltage

Saft

$5.6 \mathrm{Ah}$

$3.65 \mathrm{~V}$

$2.5 \mathrm{~V} / 4.2 \mathrm{~V}$
Operating voltage range
SafT

Nip

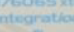

\section{Key benefits:}

- Excellent operating life in calendar, cycling and floating conditions.

- Unrivalled operating temperature range

A balancing system is embedded inside the battery to compensate the spread in the cells' voltage created by the gradients of the wide operating temperature range of the battery.
The balancing is activated only during few maintenance cycles that take place during the long term storage phases (On-ground and Cruise).

As soon as the battery operates on a daily basis on the Martian surface, the battery is autonomously balanced and does not require any external action.

The isolation switch is a latching type allowing several ON/OFF cycles.

It disconnects the battery from the rover when it is not needed -or only from time to time- especially during the storage periods. It will be finally closed prior to the descent to the Martian surface and will remain closed for the full duration of the on-surface mission.

The battery main performances are sump up in the table below.

Table 2: Battery Fact Sheet

\begin{tabular}{|l|l|}
\hline Parameter & Value \\
\hline Technology & Li-ion \\
Nameplate energy & $1140 \mathrm{Wh}$ \\
Operating Voltage & $21.0 \mathrm{~V}$ to $29.4 \mathrm{~V}$ \\
Mass & $<10.5 \mathrm{~kg}$ \\
Dimensions & $300 \times 375 \times 100 \mathrm{~mm}$ \\
& Up to $3.0 \mathrm{~A} @ \mathrm{~T}<0^{\circ} \mathrm{C}$ \\
Charge current & Up to $5.2 \mathrm{~A} @ \mathrm{~T}>0^{\circ} \mathrm{C}$ \\
Discharge current & Up to $15 \mathrm{~A}$ \\
\hline
\end{tabular}

The battery volume requirement was very challenging due to limited and tortuous space within the Rover bathtub.

The mass requirement was also very ambitious due to late development of the battery compared to the other equipments.

The battery is using mechanical parts made of Aluminium Beryllium alloy to keep the mass as low as possible.

\section{ELECTRICAL PERFORMANCES}

The electrical performances of the battery rely mainly on the type of cell which was selected.

The choice was based on the following criteria:

- A limited degradation during the high temperature phases.

- A good energy restitution when charged and discharge at low temperature on the Martian surface.

- A good ability to cycle to achieve the maximum duration on surface.

- A good energy density to limit the mass of the battery to the lowest achievable figure. 
The acceptance tests carried out on the EM battery (Engineering Model) gave the following performances:

Table 3: EM Battery performances

\begin{tabular}{|l|r|r|r|}
\hline \multirow{2}{*}{\multicolumn{1}{|c|}{ Performance }} & \multicolumn{3}{|c|}{ Temperature } \\
\cline { 2 - 4 } & $\mathbf{- 2 0}^{\circ} \mathbf{C}$ & $\mathbf{+ 2 5}^{\circ} \mathbf{C}$ & $\mathbf{+ 5 5}^{\circ} \mathbf{C}$ \\
\hline Energy $(\mathrm{Wh})$ & 909 & 1145 & 1128 \\
Internal resistance $(\mathrm{m} \Omega)$ & 124 & 46 & 46 \\
\hline
\end{tabular}

Because of the limited time for the development of the battery, and in order to assess the performances of the battery along the mission; it was decided to carry out three life-tests on cells, one for each critical phase of the mission (pre-launch encapsulated/cruise/ on-surface).

These life-tests include a margin of 1.5 times (on the duration for the calendar tests and on the number of charge/discharge cycles for the cycling tests).

The figures hereafter are showing the irreversible energy losses due to the ageing of the cells during the life-tests.

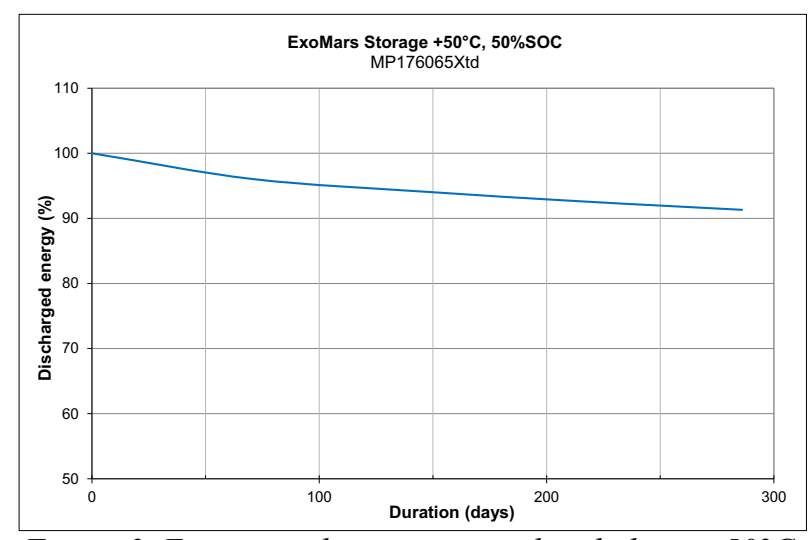

Figure 3. Energy evolution, encapsulated phase $+50^{\circ} \mathrm{C}$.

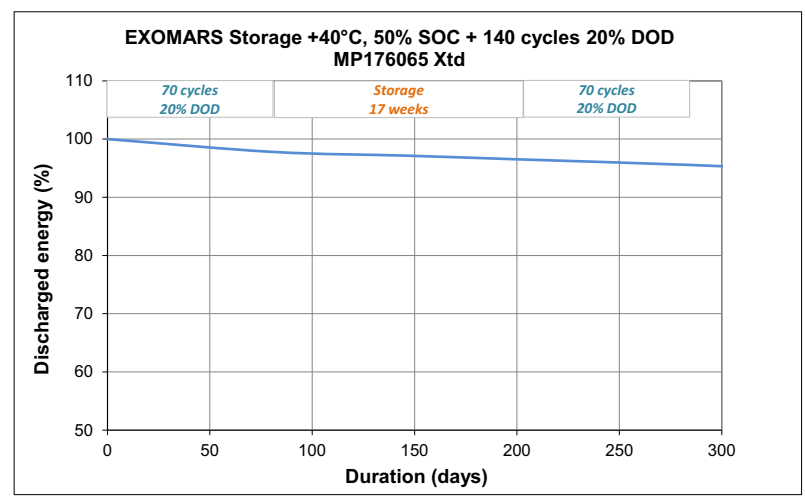

Figure 4. Energy evolution, Cruise phase $+40^{\circ} \mathrm{C}$.

The cell state of charge is $50 \%$ during these two phases.

The figures emphasis that the degradation of performances between the cruise phase (mix of calendar $\&$ cycling) at $+40^{\circ} \mathrm{C}$ is half of those of the encapsulated phase at $+50^{\circ} \mathrm{C}$; showing the criticality of the elevated temperature in the ageing of the cells.

The life-tests were also able to estimate the cell selfdischarge during the storage phases.

The results show that the higher temperature, the higher self-discharge:

$1.5 \mathrm{mV} /$ day (roughly $1.1 \%$ per month) at $+40^{\circ} \mathrm{C}$;

$0.2 \mathrm{mV} /$ day (roughly $1.7 \%$ per month) at $+50^{\circ} \mathrm{C}$.

The on Martian surface life test exhibit an outstanding performance as it exhibits no loss after the entire phase when charging the battery at $-10^{\circ} \mathrm{C}$ and discharging at $20^{\circ} \mathrm{C}$ as shown on Fig. 5 below.

We can also notice that the recovered energy is sensitive with the temperature.

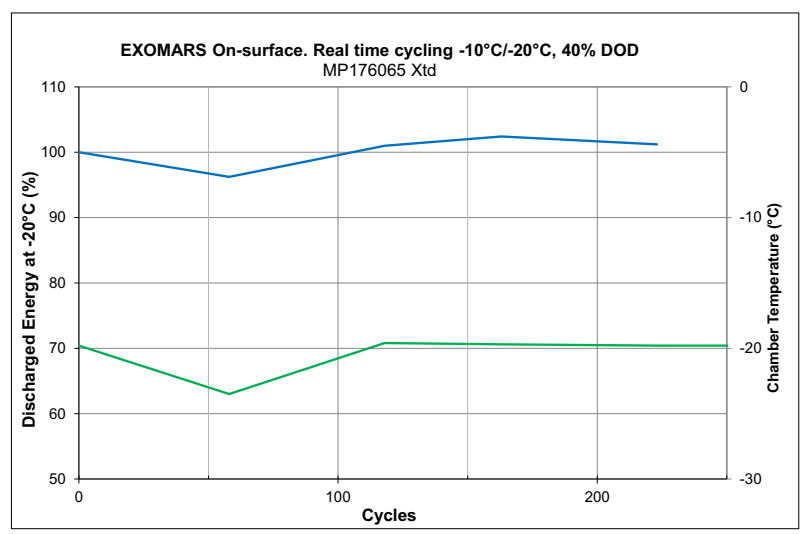

Figure 5. Energy evolution, On Mars Surface $-20^{\circ} \mathrm{C}$.

The end-of-life performances are assessed based on the above life-tests results.

The performances are excellent and in-line with the requirements of the need.

Table 4: Energy versus life phase

\begin{tabular}{|l|c|c|}
\hline Phase & Energy & \multicolumn{1}{c|}{ Conditions } \\
\hline Beginning of Life & $1140 \mathrm{Wh}$ & $+50^{\circ} \mathrm{C}, 50 \% \mathrm{SOC}$ \\
\hline $\begin{array}{l}\text { End of Prelaunch, } \\
\text { encapsulated }\end{array}$ & $1020 \mathrm{Wh}$ & $+40^{\circ} \mathrm{C}, 50 \% \mathrm{SOC}$ \\
\hline End of Cruise & $980 \mathrm{Wh}$ & $+40^{\circ} \mathrm{C}, 50 \% \mathrm{SOC}$ \\
\hline $\begin{array}{l}\text { End of On Mars } \\
\text { Surface / } \\
\text { End of Life }\end{array}$ & $790 \mathrm{Wh}$ & $\begin{array}{l}-20^{\circ} \mathrm{C}, 40 \% \mathrm{DOD} \\
\mathrm{cycling}\end{array}$ \\
\hline
\end{tabular}




\section{THERMO-MECHANICAL DESIGN}

There was almost no flexibility on the mechanical and thermal interface of the battery, as already said, due to the late development of the equipment in the timeline of the rover program. For example, the type and location of the feet was frozen. This is additional challenges for the thermal and mechanical performances of the battery.

The thermal design is critical as the temperatures surrounding the battery are swinging in a wide range.

Passive and active thermal controls are necessary to keep the battery temperature compatible with the operating range of the cells.

The passive thermal control uses feet equipped with thermal spacers that limit the conductive thermal flux between the battery and its mounting plane.

The external surfaces of the battery are covered with a low emissivity metallized tape to reduce the radiative coupling with the cold walls of the Rover.

The active thermal control is almost traditional with two types of heaters and thermal sensors.

One heater keeps the battery minimum temperature over a given threshold (the "survival heater") whereas the second one ("the warm-up heater") aims to pre-heat the cells to allow the charge process. This way, it is limiting the degradations during the cycling of the battery.

The following figures are giving a view of the cells temperatures in cold and hot cases on the Martian surface phase of the mission.

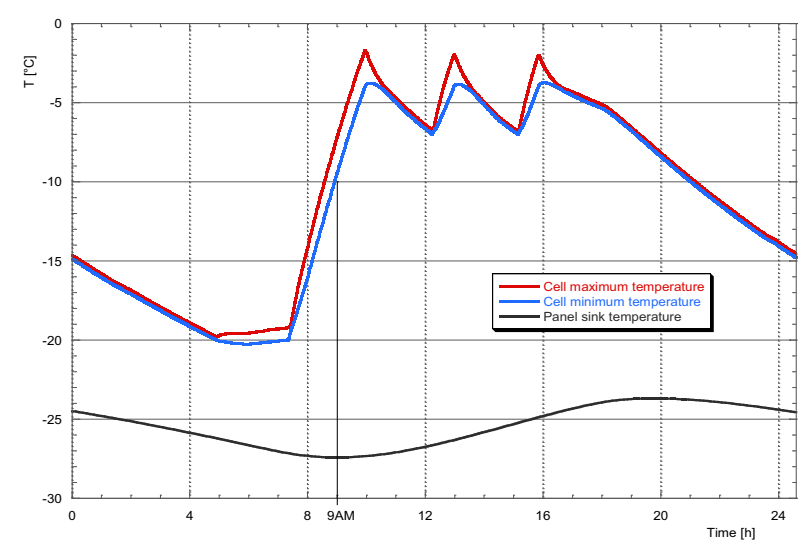

Figure 6. Cells' temperature, On Mars Surface, 1 sol, Cold case $\left(-27^{\circ} \mathrm{C}\right)$.

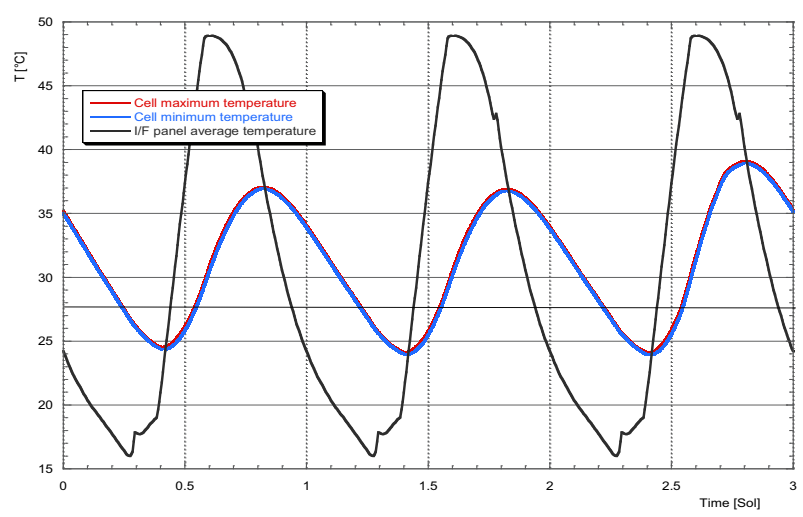

Figure 7. Cells'temperature, On Mars Surface, 3 sols, Hot case.

Another point to highlight is the fact that the launch temperature will be $+50^{\circ} \mathrm{C}$. Then the harsh vibrations and pyro-shocks will induce stresses in the materials when exposed to this non-standard temperature for a spacecraft battery at the time of a launch.

Besides these environmental induced stresses during the launch, some lower level vibrations and shocks will be seen by the battery during the separation from the descent module and the touch down on the Martian surface.

Moreover, the temperature gradients through the thermal spacers between the mounting plane and battery structure are generating additional thermo-elastic loads which had to be carefully looked at during the development.

\section{PLANETARY PROTECTION}

As the main scientific objective of the mission is to search for traces of past and present life, it is of the utmost importance to have a sterile battery; even if it is not directly in contact with the samples to be analysed.

It is quite a new and unusual requirement for a battery. Then it was a great challenge to manufacture the Exomars Rover battery in such sterile conditions.

The planetary protection requirement can be met by the following means:

- Battery design

- Manufacturing facilities

- Test facilities

- Packaging design

- Process control with assays and bioburden measurement

The battery is designed to ease the cleaning by means of smooth surfaces and easy access to surfaces to be cleaned. The material selection was also critical and non-metallic ones were screened before use inside the battery. 
The battery is assembled in a cabinet with biocontrol similar to those used in medical labs (see picture hereafter). This cabinet is further located in an ISO 8 class clean room.

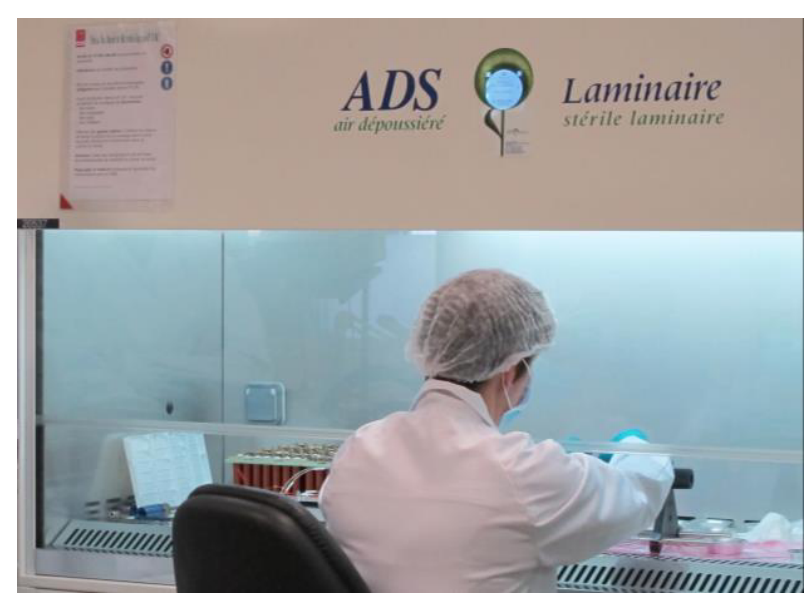

Figure 8. Sterile cabinet in ISO 8 clean room.

Prior to the assembly, all the parts are decontaminated with sterile IPA (IsoPropyl Alcohol) or other technics and the personnel are wearing sterile garments (gown, gloves, face mask...) similar to conditions as in a hospital operation room.

The contamination level is controlled and assays are performed on the battery with swabs. The bioburden load is assessed according to the ESA ECSS-Q-ST-70$55 \mathrm{C}$.

The main requirement applicable to the battery is a bioburden less than 1000 spores $/ \mathrm{m}^{2}$. The first assays done on the EM battery manufactured without all the specific dispositions shows around 500 spores $/ \mathrm{m}^{2}$.

\section{REFERENCES}

1. Stephane Zimmermann (2009). The ExoMars Rover Power System. NASA battery workshop, 2009

2. Goeff Dudley (2010). ExoMars Rover Battery Modelling \& Life Tests. NASA battery workshop, 2010

3. Rich Ewell (2010). Mars Exploration Rovers: 1 Year and Counting. NASA battery workshop. 